\title{
AQUISIÇÃO E CRIAÇÃO DE CONHECIMENTO NA INDÚSTRIA DE ALTA TECNOLOGIA
}

\section{KNOWLEDGE ACQUISITION AND CREATION IN THE HIGH-TECH INDUSTRY}

\author{
Juliano Pavanelli Stefanovitz \\ Mestrando em Engenharia de Produção \\ Universidade de São Paulo - Escola de Engenharia de São Carlos \\ Departamento de Engenharia de Produção \\ Avenida Trabalhador Sãocarlense, 400 - Centro, São Carlos-SP Brasil 13566-590 \\ Telefone: (16) 3373-9428, E-mail: julianops@prod.eesc.usp.br

\section{Marcelo Seido Nagano, Dr \\ Professor Doutor} \\ Universidade de São Paulo - Escola de Engenharia de São Carlos \\ Departamento de Engenharia de Produção \\ Avenida Trabalhador Sãocarlense, 400 - Centro, São Carlos-SP Brasil 13566-590 \\ Telefone: (16) 3373-9428, E-mail: drnagano@usp.br
}




\title{
RESUMO
}

O presente trabalho explora os novos desafios advindos da ascensão de abordagens que procuram enxergar as organizações sob a ótica do recurso conhecimento. Reconhece-se, neste contexto, a importância crescente de se entender os mecanismos através dos quais as organizações adquirem, armazenam, disseminam e criam conhecimentos. Esta pesquisa analisa os processos de aquisição externa e criação interna de conhecimento na indústria de alta tecnologia, ambiente no qual, reconhecidamente, se faz uso intensivo do conhecimento. Um estudo de caso de uma Divisão de P\&D de empresa do ramo de automação industrial vencedora do Prêmio FINEP de Inovação Tecnológica é apresentado. Nele, além do mapeamento dos canais de aquisição de conhecimentos do ambiente externo, é efetuada a análise dos processos de conversão entre os tipos de conhecimentos observados nas atividades envolvidas no desenvolvimento de seus produtos.

Palavras-chave: Conhecimento, Indústria de Alta Tecnologia, Desenvolvimento de Produtos.

\begin{abstract}
This paper explores the new challenges that come with the emergence of knowledge-based approaches on organizational studies. It is widely recognized, in this context, the increasing importance of understanding the processes through which companys acquire, storage, disseminate and create knowledge. This research analysis the knowledge creation and external acquisition processes in the high-tech industry, environment in which intensive use of knowledge is made. For that, it presents a case study of an R\&D Division of a company present in the industrial automation market. In recognition of its innovative competence, this company won the FINEP Prize - Technological Innovation. In this study, besides the identification of the main external knowledge sources, an analysis of the knowledge types conversion observed in its product development activities is made.
\end{abstract}

Key-words: Knowledge, High-Tech Industry, Product Development.

\section{INTRODUÇÃO}

Intensas transformações sociais, econômicas e tecnológicas vêm redesenhando a atividade produtiva ao colocarem o conhecimento como principal recurso na criação de vantagens competitivas e no sucesso dos empreendimentos, especialmente em setores de alta tecnologia. Este contexto tem despertado o interesse por estratégias e métodos que auxiliem a criação, aquisição, gerenciamento e, principalmente, a materialização de conhecimentos na forma de inovação em produtos e serviços.

Segundo Drucker (1993), as indústrias que passaram para o centro da economia nos últimos anos se baseiam na produção e distribuição de conhecimento e informação, e não na 
produção e distribuição de bens físicos. Nonaka e Takeuchi (1997) afirmam que, nessa nova economia, onde a única certeza é a incerteza, a única fonte segura de vantagens competitivas é o conhecimento. Numa era em que se assiste a uma rápida dinâmica dos mercados, na qual novas tecnologias se proliferam, produtos inovadores surgem em curtos períodos de tempo e novos competidores constantemente invadem a arena competitiva, as companhias devem ser cada vez mais capazes de gerar e obter novos conhecimentos e transformá-los em produtos e serviços para sobreviverem.

Este cenário exige a formulação de novas reflexões, capazes de explicar a fisionomia dos processos intensivos em conhecimento. No entanto, apesar de grande parte da produção científica relatar tal necessidade, poucas pesquisas ligadas à Gestão do Conhecimento (GC) se aventuram a sair da superficialidade conceitual em direção a um entendimento mais profundo da natureza e da dinâmica do conhecimento no ambiente organizacional.

O presente artigo tem por objetivo a investigação dos processos pelos quais as organizações podem adquirir conhecimento do ambiente externo ou criar novos conhecimentos internamente. Para tanto, efetua inicialmente revisão da literatura ligada ao assunto, com destacada atenção para teorias consolidadas que fundamentaram as bases conceituais da GC nos últimos anos. Enfoque especial é dado para abordagens que analisam a inserção destes modelos em ambientes de Pesquisa e Desenvolvimento (P\&D) de indústrias de alta tecnologia.

Após a revisão bibliográfica, é apresentado um estudo de caso na Divisão de P\&D de uma empresa brasileira de avançada tecnologia em automação industrial. Neste estudo, são evidenciados os processos que sustentam e fomentam a criação de novos conhecimentos e as formas encontradas pela Divisão de P\&D para adquirir continuamente conhecimentos externos ligados ao seu ramo de atuação.

\section{REVISÃO CONCEITUAL}

\subsection{Teoria Japonesa de Criação do Conhecimento Organizacional}

A necessidade de se redesenhar os processos organizacionais em torno do conhecimento exige um entendimento inicial sobre a natureza deste recurso. Segundo Nonaka e Takeuchi (1997), pode-se classificar o conhecimento em dois tipos: o conhecimento 
explícito - formal, sistemático, quantificável, facilmente disseminado - e o conhecimento tácito - pessoal, subjetivo, de difícil formalização, armazenado nas mentes dos indivíduos.

Estes autores são responsáveis pela consolidação de uma abordagem que mapeia os processos pelos quais novos conhecimentos são criados no contexto organizacional. É proposto modelo dinâmico da criação de conhecimento que se ancora na interação social entre os conhecimentos tácito e explícito, em particular nos quatro processos de conversão (socialização, externalização, combinação e internalização - SECI) existentes entre eles, conforme mostrado na Tabela 1.

Tabela 1: Conversões entre os tipos de conhecimento.

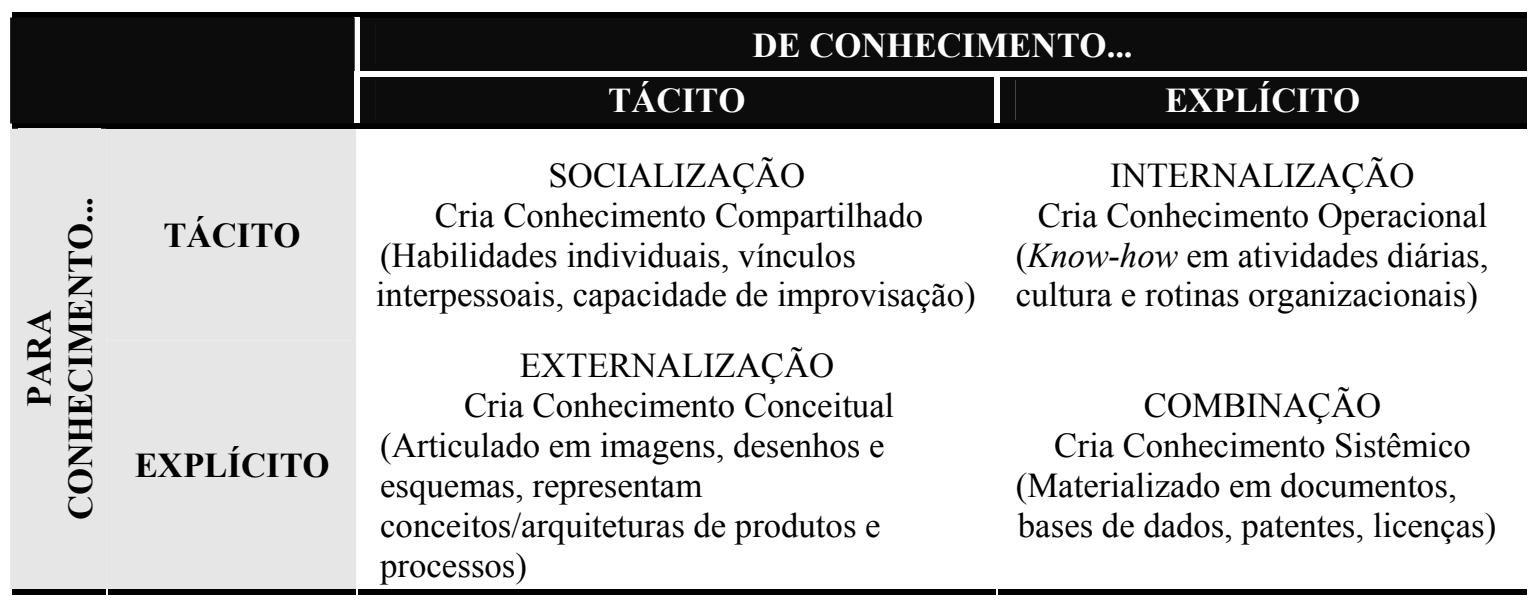

Fonte: Adaptado de Nonaka, Toyama e Konno (2000).

A chamada espiral de criação do conhecimento tem início com a socialização, processo de conversão de novos conhecimentos tácitos por meio de experiências compartilhadas em interações sociais e técnicas. Por ser de difícil formalização, este tipo de conhecimento só pode ser obtido por meio de experiências diretas e ações de caráter mais prático. O conhecimento tácito criado é articulado na externalização, onde ele é explicitado e compõe base conceitual para produção de novos conhecimentos na forma de imagens e documentos.

O processo de combinação consiste na reunião, edição e processamento de conhecimentos explícitos gerando conhecimentos explícitos mais complexos ou sistematizados que são, por suas vezes, disseminados na organização ou comunidade. Por fim, 
no processo de internalização, o conhecimento explícito, materializado, é aplicado, usado em experiências práticas e compõe a base cognitiva para novos processos.

Para ilustrar essa abordagem, Nonaka e Toyama (2003) exploram o conceito de $B a$, palavra de origem japonesa usada para representar o contexto compartilhado e dinâmico no qual o conhecimento é criado, disseminado e utilizado. Uma organização criadora de novos conhecimentos pode ser entendida como uma configuração orgânica de vários $B a$ 's, onde os indivíduos interagem entre si baseados no conhecimento que eles possuem e nos significados que eles criam. Quando se enxerga a empresa sob esta ótica, ao invés da tradicional visão estrutural, pode-se identificar que tipos de conhecimentos devem ser criados por que tipos de pessoas, e quais interações devem ser estimuladas para potencializar o desempenho de todo o processo produtivo.

Os autores defendem que existe um conjunto de condições necessárias para que se tenha o desencadeamento da espiral SECI e a construção de $B a$ 's efetivos. São elas: intenção, autonomia, flutuação e caos criativo, redundância e variedade de requisitos (NONAKA e TAKEUCHI, 1997).

Os elementos até aqui apresentados são integrados num modelo único, o qual descreve as etapas do processo ideal de criação de conhecimentos (NONAKA e TAKEUCHI, 1997):

- Compartilhamento do conhecimento tácito: etapa correspondente à socialização, na qual um campo de interação entre os indivíduos permite a troca de experiências, insights e modelos mentais;

- Criação de conceitos: etapa correspondente à externalização, responsável por tornar explícitos sob a forma de conceitos os conhecimentos tácitos trocados na etapa anterior;

- Justificação dos conceitos: etapa na qual os indivíduos filtram conceitos e justificam a pertinência e importância destes para a organização;

- Construção de um arquétipo: conversão de conceitos em arquétipos e elementos mais concretos e tangíveis, como protótipos de produtos;

- Nivelamento do conhecimento: em processo também denominado difusão interativa, o conhecimento criado é disseminado para outras pessoas da mesma divisão, de outras divisões ou até a componentes externos à organização.

Como pode ser visto, a Teoria Japonesa apresenta ingredientes teóricos de diferentes naturezas, dimensões e escopos. A Figura 1 integra a espiral SECI, as condições capacitadoras e as etapas do processo de criação de conhecimentos num modelo que contempla o conhecimento em suas dimensões tácito/explícito e interno/externo à organização. 


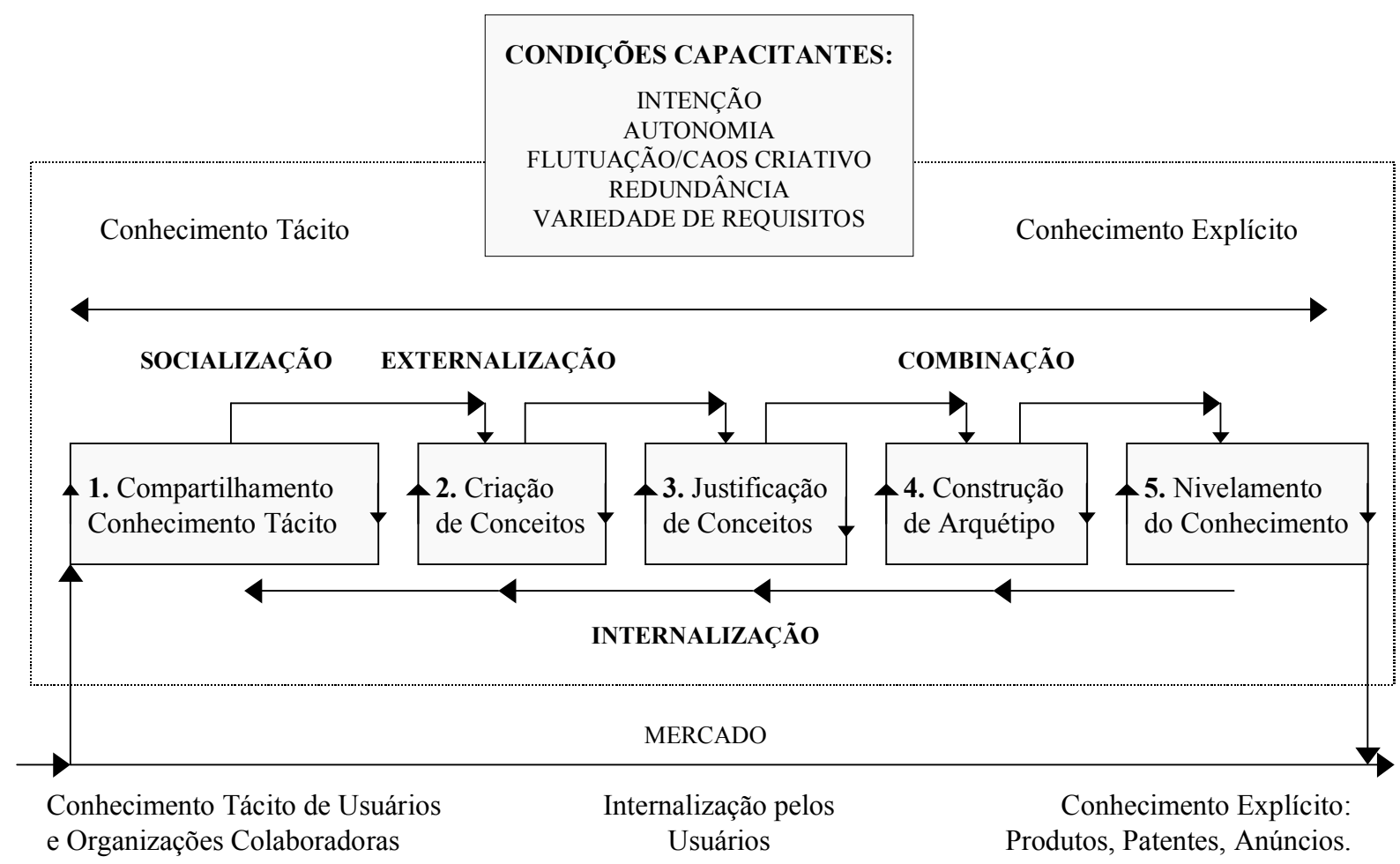

Figura 1: Modelo japonês integrado do processo de criação de conhecimentos Fonte: extraído de Nonaka e Takeuchi (1997).

Estabelecido este arcabouço teórico referente à criação de conhecimentos, a próxima seção se encarrega de discutir os modelos gerenciais mais apropriados para o desenrolar deste processo.

\subsection{O Modelo Gerencial e a Criação de Conhecimento Organizacional}

Intenso debate ocorre acerca do papel desempenhado pela média gerência nos novos modelos organizacionais. A visão ocidental tende a considerar que a importância desta camada organizacional reduzir-se-á gradativamente com o passar do tempo (DRUCKER, 1993). Em contrapartida, a escola japonesa de criação do conhecimento sintetizada em Nonaka e Takeuchi (1997) defende que os gerentes de nível médio exercem papel central na nova dinâmica produtiva, por efetuarem a conexão entre duas dimensões do conhecimento organizacional. Numa esfera superior eles são os responsáveis por assimilar a visão estratégica da alta direção e, pelo seu vasto conhecimento acumulado, transformá-la em algo mais palpável, explicitar o conhecimento necessário para sua realização e gerenciar as tarefas necessárias dentro das equipes. Já numa esfera mais baixa, são fundamentais na extração do 
conhecimento tácito dos especialistas presentes na linha de frente da organização. Assim, por efetuarem a ligação entre o mundo estratégico e o operacional, transformando as diretrizes do primeiro e as habilidades do segundo em produtos, os gerentes médios são os verdadeiros "engenheiros do conhecimento" (NONAKA e TAKEUCHI, 1997). A Tabela 2 apresenta uma comparação entre três tipos de estruturas gerenciais relacionadas ao modo como o conhecimento é criado na organização.

Tabela 2: Comparação entre os Modelos Gerenciais de Criação do Conhecimento.

TOP-DOWN

Alta direção

do conhecimento

Conhecimento acumulado

Conversão do conhecimento

Comunicação e disseminação do conhecimento

Ponto fraco
Explícito

Foco em Combinação

e Internalização

Ordens/Instruções

Grande dependência

da alta direção
ВOTTOM-UP

MIDDLE-UP-DOWN

Indivíduo empreendedor Média gerência

Tácito

Explícito e Tácito

Foco em Socialização e

Externalização

Conversão em Espiral SECI

Princípio da Auto-

Organização

Diálogo e uso de metáfora/analogia

Custo de coordenação

dos indivíduos
Exaustão humana/Custo da redundância

Fonte: Adaptado de Nonaka e Takeuchi (1997).

Para melhor acomodar o fluxo de conhecimento e fomentar as conversões de conhecimento que compõem a espiral SECI, Nonaka e Takeuchi (1997) propõem uma nova estrutura organizacional, denominada Middle-Up-Down, na qual a criação do conhecimento é centrada na média gerência em processo que envolve tanto a alta administração quanto os funcionários de linha de frente. Segundo eles, esta estrutura é mais preparada para alavancar o processo de criação do conhecimento do que aquelas nas quais o processo de inovação parte sempre do topo hierárquico (Top-Down) ou das equipes de linha de frente (Bottom-Up).

\subsection{Aquisição de Conhecimento em Unidades de P\&D}

Pesquisas recentes demonstram que o Processo de Desenvolvimento de Produtos (PDP) de alta complexidade tecnológica tipicamente requer integração de conhecimentos heterogêneos para a obtenção de efeitos sinérgicos (PARIKH, 2001; SUH, 2004). 
Evidentemente, toda esta gama de conhecimentos necessários não pode ser inteiramente criada dentro da organização - nem pode ser obtida de apenas uma fonte. Logo, deve-se entender uma organização que faz uso intensivo de conhecimento como uma célula inserida num arranjo dinâmico de $B a$ 's composto por outras empresas, organizações setoriais, universidades e institutos de pesquisa, elementos interconectados por contínuas trocas de conhecimento (BRANNBACK, 2003).

Powell (1998) chama atenção para a importância de que este posicionamento da empresa numa rede de conhecimentos contemple um rol heterogêneo e interdependente de elementos. Segundo ele, mais do que o estabelecimento de link sólido e disciplinado com uma única fonte de conhecimento, faz-se necessário estabelecer vínculos reais com uma gama diversificada de instituições que possuam interesses em determinada área de conhecimento.

Neste contexto, Brannback (2003) ratifica a importância de contexto adequado para alavancar a espiral SECI e a construção de ativos de conhecimento num $B a$ e entre $B a$ 's. Assim, as práticas de GC em grupos de P\&D devem alinhar efetivamente o fluxo do conhecimento existente entre os indivíduos, entre as unidades de pesquisa, e através das fronteiras organizacionais que conectam a companhia ao ambiente (PARIKH, 2001). Em concordância com essas idéias, Corso e Paolucci (2001) defendem que, especialmente quando se lida com produtos de alta complexidade, a gestão efetiva da inovação dos produtos é aquela capaz de permitir o processamento e a transferência de grandes quantidades de informação entre projetos e por integrar conhecimentos oriundos de diferentes fontes, internas e externas.

Portanto, o mapeamento das fontes críticas de conhecimento que sustentam as atividades de P\&D é de grande importância para a identificação das reais fontes de valor e para um eficiente direcionamento de esforços organizacionais. A Tabela 3 identifica as fontes mais relevantes e as classifica em suas dimensões principais - interna ou externa, provedora de conhecimento tácito ou explícito.

Num estudo que investiga a criação de redes de conhecimento em áreas de $\mathrm{P} \& \mathrm{D}$, Brannback (2003) destaca o grande impacto que a participação de funcionários em comunidades científicas e industriais pode trazer no estabelecimento de interações efetivas de criação de conhecimento e aprendizagem organizacional.

No sentido de se buscar uma aproximação entre os conceitos de GC e as etapas do PDP, Silva e Rozenfeld (2002) descrevem um método de avaliação da GC no PDP com foco na avaliação da ocorrência dos quatro tipos de conversões do conhecimento nas quatro dimensões do PDP: Estratégia, Organização, Atividades/Informações e Recursos. 
Tabela 3: Fontes de Conhecimento em P\&D.

\begin{tabular}{|c|c|c|}
\hline & INTERNA & EXTERNA \\
\hline \multirow{6}{*}{$\begin{array}{l}\text { Conhecimento } \\
\text { Tácito }\end{array}$} & Experiência acumulada na organização & Especialistas/consultores do ramo \\
\hline & Intuição/Insight & Melhores práticas do ramo \\
\hline & Formação acadêmica dos indivíduos & Relacionamentos interorganizacionais \\
\hline & Formação cultural dos indivíduos & Clientes \\
\hline & Relacionamentos intraorganizacionais & Pesquisadores acadêmicos \\
\hline & Especialistas/Pesquisadores & Outras instituições de pesquisa \\
\hline \multirow{7}{*}{$\begin{array}{l}\text { Conhecimento } \\
\text { Explícito }\end{array}$} & Banco de dados da organização & Banco de dados externos \\
\hline & Sistemas de informação & Produtos e manuais da concorrência \\
\hline & Procedimentos operacionais padronizados & Artigos acadêmicos \\
\hline & Atas de reuniões & Manuais de especificação \\
\hline & Documentos técnicos e protótipos & Normas Industriais \\
\hline & Manuais de produtos & Patentes externas \\
\hline & Patentes & Parcerias com outras empresas \\
\hline
\end{tabular}

Fonte: Adaptado de PARIKH (2001).

Nonaka et al. (2000) defendem que o processo de obtenção de conhecimentos do ambiente externo não pode ser encarado como uma simples relação input-output. Segundo eles, deve-se entender esse processo como uma interação dinâmica de forte componente tácito, amplamente influenciado por rotinas e habilidades organizacionais e que requer tempo, intensos esforços corporativos e forte capacidade interna para uma assimilação efetiva. Este conjunto de abordagens até aqui discutido alicerçou a construção do estudo apresentado a seguir.

\section{METODOLOGIA}

A natureza do problema de pesquisa proposto e a imaturidade conceitual das novas abordagens organizacionais voltadas para o conhecimento sugerem a utilização de uma pesquisa do tipo exploratória. Segundo Roesch (1999), as investigações exploratórias são bastante adequadas para situações como esta, nas quais o projeto envolve temas ainda pouco estudados.

Adotou-se nesta investigação a metodologia do Estudo de Caso, que, segundo Yin (2001), torna possível a realização de análise empírica de fenômeno contemporâneo no mundo real. Num estágio inicial, a pesquisa consistiu da análise de fontes secundárias como referências bibliográficas e pesquisas acadêmicas. 
Num segundo estágio, fontes primárias foram utilizadas para a obtenção de informação, num processo de interação real, durante 15 meses de contato entre a investigação e o objeto estudado. Além do acesso praticamente irrestrito à documentação ligada ao tema na empresa, a coleta de dados se concretizou através da observação direta, da observação participante em projetos de desenvolvimento por parte de um dos autores, e de entrevistas informais com mais de 50 funcionários da Divisão de $\mathrm{P} \& \mathrm{D}$, dentre os quais se encontram engenheiros, gerentes e o diretor da unidade. Tal proximidade fortaleceu a capacidade de análise das informações obtidas e de identificação do cenário encontrado.

\section{ESTUDO DE CASO}

\subsection{Caracterização da Empresa Pesquisada}

A empresa estudada está presente no mercado de automação industrial há mais de 30 anos, teve surgimento fortemente ligado ao setor sucroalcooleiro e conta hoje com aproximadamente 1200 funcionários. Apresenta posição de destaque no nicho em que atua, acentuada por importante presença no mercado internacional por meio de representações e filiais estrategicamente distribuídas em 10 países.

Possui como diferenciais competitivos, inequivocamente, sua forte orientação ao desenvolvimento de novas tecnologias e sua ampla capacidade e flexibilidade para inovar. Tais afirmações são corroboradas pelos inúmeros prêmios de inovação que já recebeu, com destaque especial para o Prêmio FINEP de Inovação Tecnológica, pela consolidação de parcerias internacionais para transferência de tecnologia e pelo grande número de patentes registradas nos EUA (13 já registradas e outras 30 em andamento).

O início de sua empreitada no mercado externo deveu-se ao grande sucesso de suas novidades tecnológicas no mercado nacional no período que sucedeu o pró-alcool e a regulamentação das substituições de importações. Neste contexto, intensificou seus esforços no desenvolvimento de produtos inovadores e conseguiu grande visibilidade mundial. A partir de então, só fez crescer seu ritmo de desenvolvimento e a amplitude de seu portfólio de soluções, processo no qual sua Divisão de P\&D Eletrônico desempenhou papel de destaque. 


\subsection{A Divisão de P\&D Eletrônico}

\subsubsection{Organização Interna e Recursos Humanos}

Célula fundamental do processo de inovação da empresa, a Divisão de P\&D Eletrônico conta com aproximadamente 120 profissionais - $10 \%$ do total de sua força de trabalho - dentre os quais se destaca a presença de mestres e doutores formados pelas principais instituições de pesquisa do país. Na Tabela 4 são apresentados dados gerais sobre a formação dos recursos humanos presentes na Divisão de P\&D.

Tabela 4: Sumário de informações da Divisão de P\&D Eletrônico

\begin{tabular}{lc}
\hline Número de Funcionários & 120 \\
Mestres/Doutorandos/Doutores & $9(7,5 \%)$ \\
Mestrandos & $25(20,8 \%)$ \\
MBA's & $4(3,3 \%)$ \\
Funcionários com curso superior & $100(83,3 \%)$ \\
\hline
\end{tabular}

A Divisão de P\&D é organizada em torno de seis grupos funcionais que provêem recursos humanos para os projetos: Equipamentos de Campos, Comunicações, Sistemas, Aplicações, Interfaces e Industrialização. O objetivo da estruturação em grupos funcionais é a manutenção e a evolução de competências em áreas de conhecimento específicas, sendo cada um deles responsabilidade de um gerente. Sete grupos, encabeçados por supervisores, fornecem serviços que dão suporte aos grupos funcionais principais: Certificação, Informática, Marketing Interno, Testes, Layout, Qualidade e Laboratório.

A representação da estrutura interna da Divisão de $\mathrm{P} \& \mathrm{D}$, mostrada na Figura 2, ilustra a divisão dos recursos humanos nos diversos grupos funcionais. No entanto, por abstrair apenas as relações funcionais e de autoridade, não contemplando as alocações de recursos por projetos, é incompleta no que se refere à riqueza e à diversidade das relações existentes entre os integrantes da Divisão de P\&D. 


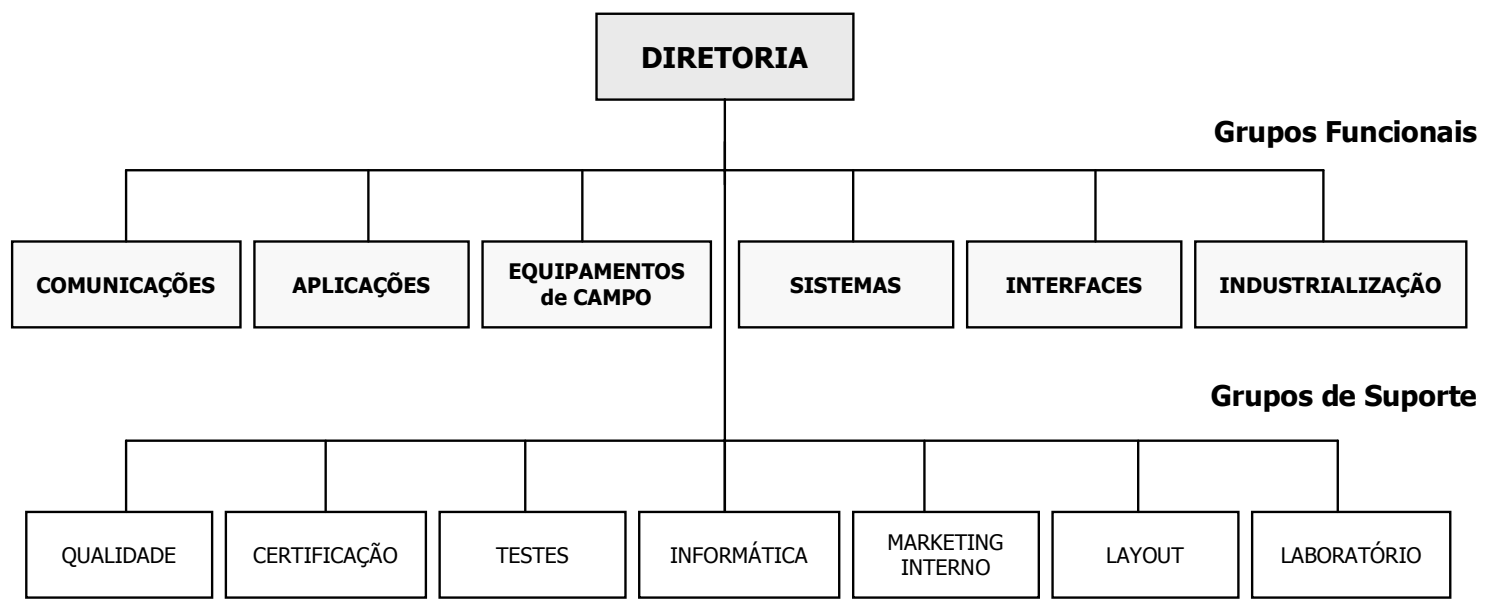

Figura 2: Estrutura interna da Divisão de P\&D Eletrônico.

Nesta unidade estudada, encontra-se ambiente corporativo singular. O clima predominante é de informalidade, liberdade e autonomia. Foram identificadas algumas políticas claras de estímulo à atividade criativa e o desenvolvimento dos funcionários, tais como a recompensa financeira individual pelo desenvolvimento de patentes e publicação de artigos em revistas técnicas especializadas, o reembolso de despesas de translado e liberação de um dia por semana para dedicação a cursos de pós-graduação.

\subsubsection{Caracterização dos Projetos e do Modelo Gerencial}

Pode-se dividir os projetos desenvolvidos na Divisão de P\&D em dois grandes grupos. No primeiro, tem-se o desenvolvimento de novos sistemas requisitados pela Divisão Comercial da companhia. Nesse caso, devem ser considerados clientes diretos da Divisão de $\mathrm{P} \& \mathrm{D}$ as próprias equipes de engenharia e vendas da empresa. Já o segundo grupo é constituído pelos projetos de parceria com outras empresas para transferência de tecnologias. O sucesso dos novos protocolos de comunicação industrial - tecnologias responsáveis pela interconexão entre vários equipamentos que efetuam a automação de uma planta industrial desenvolvidos pioneiramente pela empresa chamou a atenção de outras organizações interessadas em obter tais tecnologias. Nesse segundo tipo de projeto, a Divisão de P\&D fornece sistemas, códigos-fonte e informações técnicas quase que diretamente ao setor de P\&D da empresa contratante. 
Para se entender a dinâmica do modelo gerencial presente na Divisão de P\&D, faz-se necessário levar em consideração dois pontos: a alta complexidade do tipo de produto desenvolvido e o papel dos diferentes níveis organizacionais no PDP da empresa.

Os sistemas desenvolvidos possuem como características fundamentais o alto grau de especificidade tecnológica das partes que o integram e a forte interdependência entre seus componentes. Os produtos apresentados pela empresa ao mercado são constituídos por componentes de software e hardware inter-relacionados que vêm sendo desenvolvidos por cada um dos grupos há muitos anos, sendo perene a necessidade de cada componente acompanhar a evolução dos demais e de permitir integração que preserve o histórico tecnológico já agregado.

Assim, uma análise inicial revela que a estrutura requer especialistas focados no desenvolvimento, teste e manutenção de cada um destes componentes e líderes capazes de transmitir o conhecimento para novos integrantes, coordenar o trabalho dos especialistas e, principalmente, direcionar e acompanhar a evolução das interfaces entre os componentes concebidos de forma a propiciar uma integração harmoniosa do sistema.

Esta característica intrínseca ao produto molda de forma substancial o papel da alta direção, da média gerência e dos engenheiros de desenvolvimento no PDP. A alta direção se incumbe primordialmente de definir direções estratégicas abrangentes e acompanhar o desenvolvimento das tecnologias por uma óptica mais macroscópica e mercadológica. Para tanto, coordena o trabalho dos gerentes de desenvolvimento relativos a cada uma das áreas tecnológicas que compõem os sistemas.

$\mathrm{Na}$ linha de frente da Divisão de P\&D se encontra corpo de engenheiros de desenvolvimento responsáveis pelo estudo e pelo desenvolvimento de componentes altamente especializados de cada uma das tecnologias. Inseridos em escopos de atuação e conhecimento de alta profundidade, mas, em geral, menor extensão, torna-se difícil a concepção de processos de inovação de porte por parte destes funcionários.

Por fim, a média gerência, ratificando a literatura que fundamenta este trabalho, estabelece a interligação lógica dos conhecimentos utilizados nos níveis estratégicos e operacionais. A pesquisa mostra que os integrantes desta equipe gerencial de desenvolvimento possuem um perfil bastante homogêneo: longo tempo de serviço na companhia - o menos antigo possui 12 anos de trabalho na Divisão de $\mathrm{P} \& \mathrm{D}$; formação acadêmica e tecnológica de alto nível; e conhecimento profundo da tecnologia envolvida no escopo de seu grupo. 
A Figura 3 representa a relação entre os conhecimentos agregados e as principais atividades ligadas ao processo de desenvolvimento desempenhadas nestas três principais camadas hierárquicas da Divisão de P\&D. Neste mapeamento, sugere-se a utilização das dimensões "mercado", "arquitetura" e "componentes" para a análise dos tipos de conhecimentos e do grau de profundidade técnica no qual cada nível está inserido.

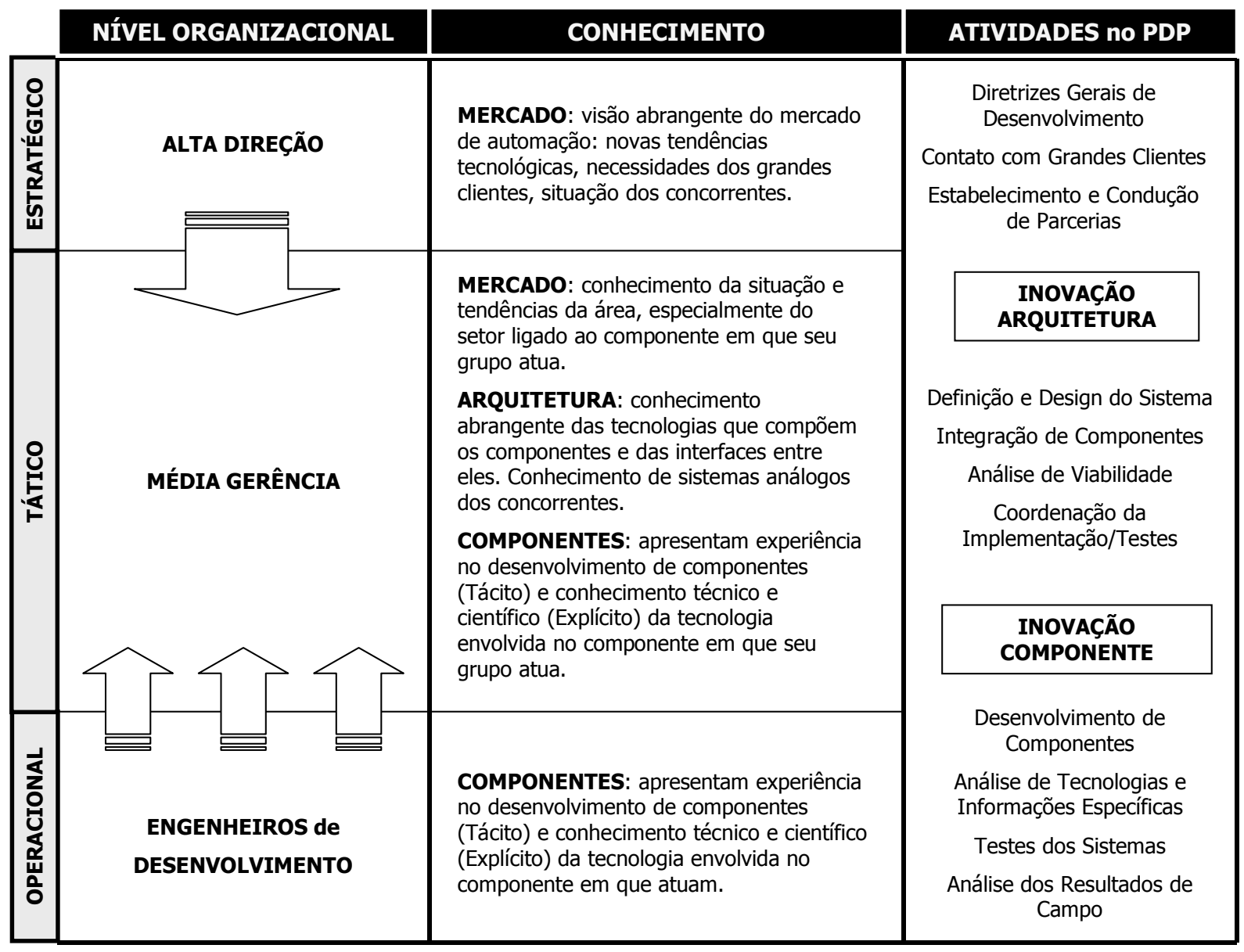

Figura 3: Níveis organizacionais e os principais conhecimentos e atividades ligados ao PDP.

Reconhece-se, assim a notoriedade do papel da média gerência no processo de criação de conhecimentos para o desenvolvimento de produtos na empresa. Por estarem conectados à estratégia de negócio da empresa pelo contato com a alta direção e às dificuldades e desafios tecnológicos específicos por meio do trabalho de coordenação dos desenvolvedores, os gerentes médios reúnem informações mercadológicas e conhecimentos técnicos que os colocam no centro da criação de novidades tecnológicas. 


\subsubsection{Relação da Divisão de P\&D com suas fontes de conhecimento}

O valor agregado aos sistemas desenvolvidos é majoritariamente constituído por complexos e extensos códigos de software. Assim, pode-se afirmar que a matéria-prima fundamental da Divisão de P\&D é conhecimento. Ao longo do processo de desenvolvimento e evolução das versões destes produtos, inúmeras fontes de conhecimento, internas e externas, são identificadas. Um dos fatores do sucesso desta célula de P\&D na criação e atualização das tecnologias da companhia é o modo intenso e versátil com que cria interfaces para troca de conhecimento com o mundo externo a ela. A Figura 4 ilustra as principais interfaces identificadas.

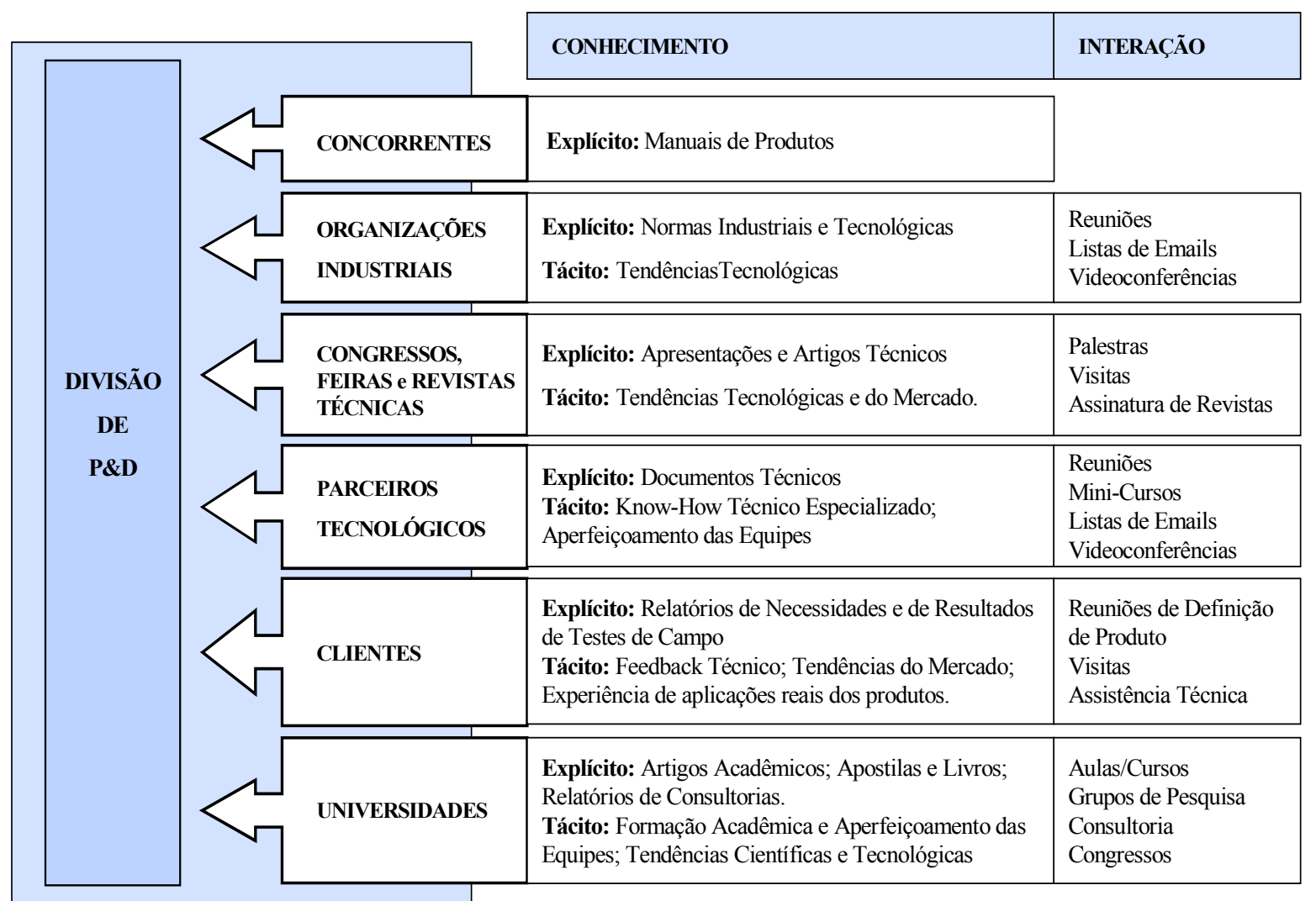

Figura 4: Interações da Divisão de P\&D com o ambiente para aquisição de conhecimento.

Dentre as interações encontradas, três canais de troca de conhecimentos merecem destaque. Em primeiro lugar, deve-se ressaltar a intensidade com que a Divisão de P\&D interage com a universidade. Além de possuir vários funcionários participando de cursos de Mestrado/Doutorado e grupos de pesquisa, outros links vêm sendo formados com o meio 
acadêmico, por exemplo, com a contratação de serviços de consultoria de pesquisadores especializados em tecnologias-chave no ramo de automação.

Em segundo lugar, chama a atenção a importância do estabelecimento de parcerias tecnológicas na composição do roteiro de aquisição de conhecimento, por meio de contratos que visam à troca de know-how técnico entre empresas do ramo. Em um exemplo recente, acordo foi firmado com empresa alemã líder no segmento de segurança industrial interessada em obter conhecimentos sobre as tecnologias de transmissão de dados desenvolvidas na Divisão de P\&D. A conexão permitiu a troca direta de conhecimento entre equipes das empresas por meio de cursos, reuniões e troca de documentos técnicos.

Por fim, chama a atenção a grande participação de funcionários da Divisão de P\&D em comunidades científicas e industriais. Dentre seus gerentes e coordenadores se encontram integrantes ativos de grupos de pesquisa de caráter científico-tecnológico e líderes e membros de importantes organizações, nacionais e internacionais, de padronização e disseminação de tecnologias.

\subsubsection{O Processo de Desenvolvimento e as Conversões de Conhecimento}

O processo de desenvolvimento, manutenção tecnológica e controle de versões dos sistemas produzidos é altamente complexo. A fim de melhor apresentá-lo no contexto de trabalho identificado na Divisão de P\&D, ele foi dividido em quatro grandes etapas: Definição do Conceito, Planejamento do Projeto e Definição da Arquitetura, Desenvolvimento e Validação, e, por fim, Transição para a Produção e Evolução. Aqui, vale destacar que, sendo a maior parte do valor encontrado no produto residente em códigos de software, a etapa de Desenvolvimento é basicamente constituída pelos esforços de programação computacional dos engenheiros de desenvolvimento responsáveis por cada componente do sistema. Apesar do objetivo de se evoluir o projeto ao longo destas etapas de forma seqüencial e unidirecional, iterações reversas e revisões/reedições de etapas anteriores são altamente freqüentes devido à constante mudança de requisitos e à identificação de limitações e entraves tecnológicos.

Conforme visto, faz-se necessário identificar os processos de conversão do conhecimento para se compreender o processo de criação do conhecimento e, conseqüentemente, a inovação. Apesar de não apresentar um grande programa ou departamento exclusivo de GC - um projeto piloto se encontra em formação - alguns 
processos sedimentados no ciclo de trabalho da Divisão de P\&D ao longo dos anos merecem atenção. A Figura 5 apresenta a relação entre as etapas de desenvolvimento e as principais atividades ligadas aos quatro tipos de conversão do conhecimento.

\begin{tabular}{|c|c|c|c|c|c|}
\hline & $\begin{array}{r}\text { NEC } \\
\text { DC } \\
\text { OPO } \\
\text { DE }\end{array}$ & $\begin{array}{l}\text { CSSIDADE } \\
\text { CLIENTE } \\
\text { TUNIDADE } \\
\text { IERCADO }\end{array}$ & $\begin{array}{r}\text { PROJ } \\
\text { ARQUIT }\end{array}$ & $\begin{array}{l}\text { TOO } \\
\text { TURA }\end{array}$ & PRODUTO \\
\hline & & Definição do Conceito & $\begin{array}{l}\text { Planejamento do Projeto } \\
\text { Definição da Arquitetura }\end{array}$ & $\begin{array}{l}\text { Desenvolvimento e } \\
\text { Validação }\end{array}$ & $\begin{array}{c}\text { Transição para } \\
\text { Produção e Evolução }\end{array}$ \\
\hline \multicolumn{2}{|c|}{ Conversões } & $\begin{array}{l}\text { Clientes } \\
\text { Gerência Engenharia } \\
\text { Gerência } \\
\text { Desenvolvimento }\end{array}$ & $\begin{array}{l}\text { Gerência } \\
\text { Desenvolvimento }\end{array}$ & $\begin{array}{l}\text { Equipes Desenvolvimento } \\
\text { (Gerente + Engenheiros } \\
\text { de Desenvolvimento) }\end{array}$ & $\begin{array}{l}\text { Equipe } \\
\text { Desenvolvimento } \\
\text { Equipe Engenharia } \\
\text { Equipe Treinamento }\end{array}$ \\
\hline \multirow{4}{*}{ SECI } & $\begin{array}{l}\text { Socialização } \\
\text { (Tácito-Tácito) }\end{array}$ & $\begin{array}{l}\text { Reuniões/Brainstorming } \\
\text { Visitas ao Cliente }\end{array}$ & Reuniões/Brainstorming & $\begin{array}{l}\text { Reuniões } \\
\text { Resolução de problemas em } \\
\text { conjunto }\end{array}$ & Reuniões entre as equipes \\
\hline & $\begin{array}{l}\text { Externalização } \\
\text { (Tácito-Explícito) }\end{array}$ & $\begin{array}{l}\text { Necessidade do Cliente } \rightarrow \\
\text { Documento de Requisitos } \\
\text { do Sistema }\end{array}$ & $\begin{array}{l}\text { Experiência dos Gerentes } \rightarrow \\
\text { Documento de Arquitetura } \\
\text { do Produto }\end{array}$ & $\begin{array}{l}\text { Conhecimento dos } \\
\text { engenheiros } \rightarrow \\
\text { Implementação dos } \\
\text { componentes }\end{array}$ & $\begin{array}{l}\text { Conhecimento tácito } \\
\text { acumulado no projeto } \rightarrow \\
\text { Manual do Usuário / } \\
\text { Apostilas de Treinamento }\end{array}$ \\
\hline & $\begin{array}{l}\text { Combinação } \\
\text { (Explícito- } \\
\text { Explícito) }\end{array}$ & $\begin{array}{l}\text { Documentação Técnica do } \\
\text { Cliente } \rightarrow \text { Documento de } \\
\text { Requisitos do Sistema }\end{array}$ & $\begin{array}{l}\text { Documento de Requisitos do } \\
\text { Sistema } \rightarrow \\
\text { Documento de Arquitetura } \\
\text { do Sistema }\end{array}$ & $\begin{array}{l}\text { Documento de Arquitetura do } \\
\text { Sistema } \rightarrow \\
\text { Documentação de } \\
\text { Especificação Técnica do } \\
\text { Sistema }\end{array}$ & $\begin{array}{l}\text { Toda Documentação } \rightarrow \\
\text { Manual do Usuário / } \\
\text { Apostilas de Treinamento }\end{array}$ \\
\hline & $\begin{array}{l}\text { Internalização } \\
\text { (Explícito-Tácito) }\end{array}$ & $\begin{array}{l}\text { Conhecimento explíito } \\
\text { sobre a realidade do cliente } \\
\text { é absorvido pela companhia }\end{array}$ & $\begin{array}{l}\text { Agregação de novos } \\
\text { conhecimentos aos gerentes. }\end{array}$ & $\begin{array}{l}\text { Agregação de novos } \\
\text { conhecimentos aos } \\
\text { especialistas e aumento da } \\
\text { experiência. }\end{array}$ & $\begin{array}{l}\text { Conhecimento explícito } \\
\text { acumulado no projeto é } \\
\text { transferido em } \\
\text { treinamentos práticos. }\end{array}$ \\
\hline
\end{tabular}

Figura 5: Principais conversões de conhecimento (SECI) no PDP da empresa estudada.

A gestão de conhecimentos explícitos é alicerçada pelo estabelecimento de políticas efetivas de documentação, fundamentais para o armazenamento e distribuição de conteúdos de grande profundidade técnica. A documentação dos conhecimentos envolvidos em cada etapa do projeto se mostra necessária para a alimentação correta da etapa seguinte e para o armazenamento de conhecimento organizacional que permita o resgate rápido de informações e a reconstrução de históricos de projetos. Foram encontrados processos bem estabelecidos de documentação nessas etapas:

- Documento de Requisitos do Sistema (produto da etapa de Definição do Conceito): agrega as funcionalidades e características gerais que o sistema a ser desenvolvido deve possuir;

- Documento de Arquitetura do Sistema (produto da etapa de Planejamento do Projeto/Definição da Arquitetura): reúne enorme quantidade de informações a serem 
consultadas pelos desenvolvedores. Contando com participação fundamental do gerente responsável pelo projeto, sua confecção consiste num processo exaustivo de externalização de conceitos e combinação de conhecimentos oriundos de diferentes áreas (alguns materiais observados nesta etapa ultrapassam 400 páginas).

- Documentação Técnica de software, hardware e resultados de testes concebidos pelos engenheiros de desenvolvimento na fase de Desenvolvimento e Validação;

- Manual do Usuário e Apostilas de Treinamento: De linguagem menos técnica e mais didática, servem, além de seus fins óbvios, como instrumentos de aprendizado individual para profissionais de outros setores da empresa ou desenvolvedores inseridos em outros projetos que necessitem de informações menos profundas sobre o sistema.

Verifica-se, assim, importante papel da documentação no processo de criação de conhecimentos, particularmente em duas etapas descritas na teoria japonesa: na justificação de conceitos desenvolvidos (por exemplo, para a estruturação da Arquitetura do Sistema) e na fase de nivelamento do conhecimento. Na primeira, a extensa documentação serve de veículo para a externalização e posterior apreciação, por parte dos engenheiros responsáveis pelo desenvolvimento de cada componente, dos conhecimentos criados e combinados. Nesta fase, é comum a identificação de pequenas inconsistências na arquitetura proposta documentada, ocasionando feedbacks que fortalecem o processo criativo e a robustez do produto. Tal processo de convergência e refinamento, fundamentais para o processo criativo, se torna muito mais factível e concreto na presença de documentos que materializem o conhecimento técnico ao longo sua evolução.

Na segunda, ressalta-se a importância dos documentos com estilo mais orientado ao aprendizado na disseminação do conhecimento adquirido ao longo do projeto. Ao fazer isso, tais documentos contribuem para a incorporação efetiva dos novos conhecimentos pela organização, tornando-os menos pontuais e evitando sua concentração excessiva apenas nos participantes do projeto.

\section{CONSIDERAÇÕES FINAIS}

Intensas discussões teóricas têm permeado temas ligados à Gestão do Conhecimento e muitas pesquisas surgem ratificando a importância do conhecimento no estabelecimento de vantagens competitivas. No entanto, poucos estudos encontrados fazem uso desse ferramental 
conceitual para analisar de forma efetiva os processos organizacionais - e seus atores - em que o conhecimento é criado ou adquirido.

A revisão de literatura atual no campo da Gestão do Conhecimento ressalta a importância de mecanismos que intensifiquem a relação de empresas focadas em P\&D com uma gama heterogênea de fontes de conhecimento. Além disso, a conceituação teórica que alicerça estes estudos mostra a necessidade de práticas de gestão que estimulem de forma efetiva as conversões de conhecimento no processo de criação de novos conhecimentos. Já estudos sobre a Inovação têm destacado a identificação de culturas e estruturas organizacionais que fomentem e desencadeiem o processo de inovação.

Este artigo evidencia as formas encontradas por uma Divisão de P\&D na obtenção de conhecimentos que alimentam seu processo de desenvolvimento e a mantêm tecnologicamente atualizada. $\mathrm{O}$ estudo de caso mostra a necessidade de se posicionar uma unidade que faz uso intensivo de conhecimento, como a Divisão de P\&D estudada, numa teia setorial que envolve diversos atores. Para que este posicionamento se efetive, observou-se a presença de infra-estrutura de tecnologia da informação e agilidade organizacional indispensáveis para se dialogar com uma diversificada gama de interlocutores institucionais e fontes de conhecimento.

Além disso, fazendo uso de abordagens teóricas consolidadas, o estudo ratifica a importância de se desenhar subprocessos adequados para sustentar as atividades envolvidas no desenvolvimento de produtos, de forma a estimular as conversões dinâmicas entre os conhecimentos explícito e tácito. Nesse ponto, há que se ressaltar o ambiente diferenciado em relação às demais divisões da empresa - encontrado no setor de P\&D. Políticas claras de estímulo à produção de conhecimentos e desenvolvimento acadêmico continuado se somam a um ambiente de informalidade na consolidação de uma cultura orientada para o desenvolvimento de tecnologias.

A pesquisa mostra, também, o papel fundamental exercido pela documentação ao longo das etapas do processo de desenvolvimento. Os materiais gerados constituem a base de conhecimentos explícitos que concretiza e possibilita os processos de externalização, combinação e nivelamento de conhecimentos.

O estudo mostra ainda uma grande concentração do fluxo de conhecimento na camada composta pela média gerência da Divisão de P\&D. Neste ponto, os resultados da pesquisa sugerem uma ratificação do modelo gerencial Middle-Up-Down (NONAKA e TAKEUCHI, 1997). Por integrarem diretrizes estratégicas e tendências mercadológicas a 
conhecimentos técnicos tácitos de grande profundidade, os gerentes de P\&D constituem peça chave no processo de inovação da empresa estudada. A pesquisa ressalta que este fato é intensamente reforçado pela alta complexidade tecnológica do produto. Nesse ponto, sugerese que uma análise do fluxo de conhecimento segundo as dimensões "mercado", "arquitetura" e "componente" é capaz de evidenciar este papel integrador central desempenhado pela média gerência.

Apesar da limitação óbvia inerente a este estudo - a impossibilidade de se generalizar amplamente resultados obtidos em apenas um estudo de caso - o reconhecimento do mercado e as premiações em nível nacional - maximizadas pelo Prêmio FINEP de Inovação Tecnológica - certamente intensificam o peso das lições que podem ser aprendidas com uma empresa que desenvolve tecnologia no Brasil.

\section{REFERÊNCIAS}

BRANNBACK, M. R\&D collaboration: role of $\mathbf{B a}$ in knowledge-creating networks. Knowledge Management Research \& Practice, 1, p. 28-38, 2003.

CORSO, M., PAOLUCCI, E. Fostering innovation and knowledge transfer in product development through information technology. International Journal of Technology Management, Vol. 22, pp. 126-148, 2001.

DRUCKER, P. Sociedade Pós-Capitalista. São Paulo: Pioneira, 1993.

LEONARD-BARTON, D.; SENSIPER, S. The Role of Tacit Knowledge in Group Innovation. California Management Review, Vol. 40, No.3, pp. 112-127, 1998.

NONAKA, I., TAKEUCHI, H. Criação de conhecimento na empresa. Rio de Janeiro: Campus, 1997.

NONAKA, I., TOYAMA, R., KONNO, N. SECI, Ba and Leadership: Unified Model of Dynamic Knowledge Creation. Long Range Planning, Vol. 33, pp. 5-34. 2000. 
NONAKA, I., TOYAMA, R., NAGATA, A. A Firm as a Knowledge Creating Entity: A New Perspective on the Theory of the Firm. Industrial and Corporate Change, Vol. 9, No 1, pp. 932-1292. 2001.

NONAKA, I., TOYAMA, R. The Knowledge-Creating Theory Revisited: Knowledge Creation as a Synthesizing Process. Knowledge Management Research \& Practice, 1, pp. 2$10,2003$.

PARIKH, M. Knowledge Management framework for high-tech research and development. Engineering Management Journal, Vol. 13 No 3, pp. 27-33, 2001.

POWELL, W.W. Learning from Collaboration: Knowledge and Networks in the Biotechnology and Pharmaceutical Industries. California Management Review, Vol. 40, No.3, pp. 228-240, 1998.

ROESCH, S.M.A. Projetos de estágio e de pesquisa em administração. São Paulo: Atlas, 1999.

ROZENFEld, H., FORCELlini, F.A., AMARAL, D.C., TOLEDO, J.C., SILVA, S.L., ALLIPRANDINI, D.H., SCALICE, R.K.. Gestão de Desenvolvimento de Produtos: Uma referência para a melhoria do processo. Editora Saraiva, 2005.

SILVA, S.L., ROZENFELD, H. Gestão do conhecimento no processo de desenvolvimento. Anais do Congresso Anual da Sociedade Brasileira de Gestão do Conhecimento, 1, 2002.

SUH, W., SOHN, J.H., KWAK, J.Y. Knowledge management as enabling R\&D innovation in high tech industry: the case study of SAIT. Journal of Knowledge Management, Vol. 8, No. 6, pp. 5-15, 2004.

TERRA, J.C.C. Gestão do Conhecimento: Aspectos Conceituais e Estudo Exploratório Sobre as Práticas de Empresas Brasileiras, Tese de Doutorado, USP, 1999.

YIN, R. Case Study Research. California: Sage Publications, 2001. 
Artigo recebido em $\mathrm{xx} / \mathrm{xx} / \mathbf{x x}$ e aceito para publicação em $\mathrm{xx} / \mathrm{xx} / \mathbf{x x}$ 